\title{
Academic refugees
}

\section{Robert Boyd, John Akker and Laura Wintour}

Council for Assisting Refugee Academics, London South Bank University, London SE1 6LN, UK, email r.boyd@manchester.ac.uk

A $t$ the end of last year, a symposium was held at the British Academy in London to celebrate a 75th anniversary. The anniversary was of the establishment in 1933 of a unique organisation: the Academic Assistance Council, now the Council for Assisting Refugee Academics (CARA); the Council in 1937 became formally incorporated as the Society for the Protection of Science and Learning (SPSL), and in the 1980s assumed its current title. Although a celebration, the anniversary was in reality a reason for sadness, in that, 75 years after its establishment as a shortterm measure to cope with the German Nazi government's policy of firing all Jews from their jobs, its work remains and its activities are currently more in demand than at any time since the 1930s.

The Council was founded by such luminaries as William Beveridge, the father of the welfare state, J. Maynard Keynes, the father of global economic policy, and A. V. Hill, a Nobel laureate in physiology and medicine (and Keynes's brother-inlaw). While such famous names and those of other academic leaders were of critical importance as signatories of the letter of appeal establishing the Council, an equally important ingredient was an ethos of individual personal care for academic refugees, provided from the Council's earliest days by Esther Simpson, who worked for the organisation from its inception for over four decades. Personal involvement with and support for individual academics in re-establishing a life and a career remain central to CARA's work.

Those in the specialty of psychiatry, perhaps above any other, will understand the inner desolation of losing job, status, livelihood, country and often family on becoming a refugee. Economic support without friendship is insufficient. Albie Sachs, twice a grantee of CARA and now a Justice of the Constitutional Court of the Republic of South Africa, gave an anniversary lecture at University College London in 2008. He movingly described how, on becoming a refugee, 'you feel crushed. You lose self-esteem, and although the political will remains strong you suffer... I received just the right touch of warmth of heart and practicality [from the organisation].' That was in 1966. Following a second arrival in 1988, after he had been blown up by the defence forces of the apartheid regime, losing an arm, his job, his home and his income, 'The organised love of nurses, doctors and physiotherapists was one thing: the help of the SPSL was the emotional equivalent'. But things are often not so positive. One recent refugee from Iraq, a psychiatrist, commented that losing one's country was like losing a limb but that the difficulty of becoming re-established in Britain felt like being paralysed in addition.

Several thousand individual academic refugees to the UK have been helped by CARA and its predecessors over the 75 years. Some have stayed permanently in the UK, some have gone back as conditions have improved, and others moved on to other countries as a final destination. Eighteen grantees were awarded Nobel prizes. Among those who stayed in the UK have been Ernst Chain (penicillin), Hans Krebs (Krebs cycle), Bernard Katz (neuroscience), Max Perutz (haemoglobin) and Max Born (a physicist who declined to work on the military uses of atomic fission). Ludwig Guttman, another grantee, though not a Nobel laureate, transformed paraplegia, through his clinical practice, from being a delayed death sentence to being a disability. His socialisation of those disabled by paraplegia reached its zenith with the establishment of the Paralympics Games. In the UK alone, 130 academic refugees have become fellows of learned academies such as the Royal Society and the British Academy.

At present there are over 180 academics being supported, who have come from more than 30 countries. The plight of Iraqi academics in particular has been under-publicised: over 350 have been assassinated in recent years and others have been kidnapped. Enormous numbers remain displaced in nearby countries where CARA is, for the first time, working outwith the UK in developing local support systems to provide help to refugee academics nearer home.

One, but by no means the only, reason for developing local support, where possible with others, is the difficulty of obtaining entrance for refugees into the UK and similar countries. This is not a new problem. In the early years of the Academic Assistance Council, Britain refused many refugees entry and a large number subsequently lost their lives. Britain also made it difficult for others, once admitted, to function professionally, for example by declining to recognise their medical degrees. In a panic at the start of the Second World War, alien academics in Britain - the great majority anti-Nazi refugees - were deported, some dying through torpedo attacks en route, or interned on the Isle of Man. They were gradually released only through the persistent political pressure exerted by A. V. Hill, then a Member of Parliament in addition to being an academic. At that time, many British doctors lobbied against the professional recognition of their German fellow physicians. A memo declares that 'the number of foreign medical scientists who could teach us anything could be counted on the fingers of one hand'. Seabrook (2008) suggests that, sadly, such prejudice still exists, and this matches CARA's experience; on the other hand, the efforts and support of others are also, fortunately, still frequently found.

It is perhaps unsurprising that academics (about one-third of whom in CARA's experience are in medicine or other related disciplines relevant to psychiatry) are overrepresented among refugees from the professions. When regimes are, or become, dictatorial, or where civil strife intensifies, those who 'speak truth unto power' through criticism, through pointing out alternative possibilities, or through upholding ethical standards - key academic duties - are all too likely to 
suffer job loss, imprisonment, torture or expulsion. Furthermore, the loss of the academic members of a society will, unless they can maintain skills in exile and later return, permanently affect that society's future. Germany was a world leader in scholarship before Hitler but never fully recovered its academic position (Medawar \& Pyke, 2000); the USA, Australia, Canada and the UK all gained immeasurably, as to a lesser extent did others.

The number seeking CARA's help has quadrupled in the past 3 years and continues to grow. There has been a very significant increase in the number of medical and other healthcare professionals seeking refugee status in the UK and in other countries according to our own figures. This is partly because of the situation in Iraq, where healthcare professionals are still being targeted by extreme elements, despite media reports that the situation is improving. Several hundreds have been assassinated there since 2003, mostly because they have sought to continue their work in their specialty. Also, in Zimbabwe extremely harsh conditions apply and many have gone to South Africa and neighbouring countries after finding it impossible to practise.

Practical details of how an interested reader, of whom we hope you may be one, can support the work of CARA can be found on our website, www.academic-refugees.org. Psychiatrists across the globe can do much to assist this constituency of academic colleagues by speaking up against the stigmatisation of such refugees, supporting the correct view that they are and may increasingly become key local and global assets for a better future and, importantly, helping them to become re-established in their careers.

\section{References}

Medawar, J. \& Pyke, D. (2000) Hitler's Gift: Scientists Who Fled Nazi Germany. Richard Cohen Books.

Seabrook, J. (2008) The Refugee and the Fortress: Britain and the Flight from Tyranny. Palgrave-Macmillan.

\section{Compulsory treatment in the community: concept and controversy}

\section{David Skuse}

Behavioural and Brain Sciences Unit, Institute of Child Health, London WC1N 1EH, UK, email dskuse@ich.ucl.ac.uk

0 n 3 November 2008, new powers which allowed supervised community treatment, implemented by community treatment orders, came into effect in England. These orders were presaged by the Mental Health Act 2007 and contain specific conditions with which a patient must comply. The thinking behind the new orders was that patients in the community who are likely to be nonadherent to treatment could be treated under compulsion at an early stage in a relapsing phase of their illness, in order to prevent further relapse into serious illness, which could lead to their recurrent and compulsory admission to hospital. If patients who are to be treated in the community refuse to comply, they can be held in hospital against their will for up to 72 hours and forcibly treated. They cannot be forcibly compelled to accept treatment in the community. The legislation was controversial and was by no means universally supported. Some have argued that the motivation behind the introduction of new powers to allow 'compulsory treatment in the community' was more to assuage public anxiety about the potential threat to them caused by some people with mental health problems, a threat that is arguably in the public mind far greater than reality, than to provide a more liberal regime for the management of seriously ill psychiatric patients.

Since the introduction of this legislation, the Mental Health Act Commission reports that the use of community treatment orders has far exceeded official estimates. In fact, recent reports suggest mental health services are struggling to deal with the high demand: more than 1200 people in England had been made subject to compulsory treatment 5 months after the powers were introduced. There have been delays processing the new orders because of a shortage of psychiatrists appointed to provide second opinions, who are able to authorise them.

England is not the only country to have introduced the option of compulsory treatment in the community, and in this issue we discuss the experience of a range of countries from Europe (James Strachan), the Middle East (Moody Magdy Zaky) and the Antipodes (John Dawson). Controversies are discussed by each of these authors. One key issue concerns the infrastructure that is provided to support compulsory treatment in the community or, rather, the lack of it. Another is the exact configuration of people (professionals and kin) needed to authorise such treatment, to protect the rights of the patient from potential abuse. It is particularly interesting to read the experience of New Zealand, which has had a community treatment order scheme since 1992: it seems that psychiatrists and even patients find the scheme works well, and they broadly support it. In view of this happy state of affairs, those responsible for framing legislation in other countries would be advised to learn from the New Zealand experience. 